(c) The Author(s), 2020. Published by Cambridge University Press on behalf of The Nutrition Society. This is an Open Access article, distributed under the terms of the Creative Commons Attribution licence (http://creativecommons.org/licenses/by/4.0/), which permits unrestricted re-use, distribution, and reproduction in any medium, provided the original work is properly cited.

\title{
Data-driven development of the Meal-based Diet History Questionnaire for Japanese adults
}

\author{
Kentaro Murakami ${ }^{1 *}$, Nana Shinozaki ${ }^{1}$, Tracy A. McCaffrey $^{2}$, M. Barbara E. Livingstone ${ }^{3}$ and Satoshi Sasaki ${ }^{1}$ \\ ${ }^{1}$ Department of Social and Preventive Epidemiology, School of Public Health, University of Tokyo, Tokyo 113-0033, Japan \\ ${ }^{2}$ Department of Nutrition, Dietetics and Food, Monash University, Clayton, Melbourne, VIC 3168, Australia \\ ${ }^{3}$ Nutrition Innovation Centre for Food and Health (NICHE), School of Biomedical Sciences, Ulster University, \\ Coleraine BT52 1SA, UK
}

(Submitted 20 June 2020 - Final revision received 10 November 2020 - Accepted 1 December 2020 - First published online 10 December 2020 )

\section{Abstract}

FFQ, the primary method of dietary assessment in large-scale nutritional epidemiological studies, preclude an informed evaluation of the timing of dietary intake and meal-specific dietary intake. In this study, we developed the Meal-based Diet History Questionnaire (MDHQ), a selfadministered questionnaire designed for estimating food and nutrient intakes for each meal type separately. The development was done based on a 16-d dietary record obtained from 242 Japanese adults. The MDHQ consisted of the three different parts, with a total of 196 items. Part 1 of the MDHQ asks about consumption frequency of generic food groups ( $n$ 24) for each meal type: breakfast, morning snack, lunch, afternoon snack, dinner and night snack. Part 2 of the MDHQ asks about relative consumption frequency of sub-food groups within one of the generic food groups which are asked in Part 1. Combining information derived from Parts 1 and 2 enables us to increase the number of foods we can estimate efficiently but within a limited number of questions. Part 3 of the MDHQ asks about general eating behaviours, which are intended to use in a variety of ways during dietary intake calculation. A series of calculation algorithms for food groups, energy and nutrients was also prepared. Given that the MDHQ was empirically developed based on comprehensive information on actual food consumption, this innovative tool may be promising for future epidemiological research on meal patterns and time of day of dietary intake, or chrono-nutrition research. A rigorous evaluation of validity of the MDHQ is warranted.

\section{Key words: Meal type: Dietary assessment: Validity: Meal quality: Time of day of intake}

Efforts to overcome the limitations of evaluating single nutrients and foods in isolation have led to a gradual shift in emphasis to the evaluation of dietary patterns ${ }^{(1,2)}$. Although the investigation of dietary patterns is generally performed in terms of the daily intake of individual foods or food groups ${ }^{(3-6)}$, an increasing number of studies have focused on dietary intake at the level of specific eating occasions (i.e. breakfast, lunch, dinner and snack) or meal patterns ${ }^{(7-9)}$. Studying dietary patterns at the meal level in the context of overall dietary patterns may be more pertinent when considering synergies and interactions during digestion and metabolism ${ }^{(10)}$. Characterising different meal types is particularly important because the same foods are not always consumed in the same proportions at each meal, resulting in meal-specific food combinations and different nutritional qualities by meal types ${ }^{(11-15)}$. This dietary information would be more relevant for formulating meaningful meal-based dietary guidelines and public health messages as well as for developing effective intervention strategies for promoting healthy eating.
Recent studies have suggested that not only the amount and type of food intake but also the circadian timing of food intake need to be considered, given that food intake, appetite, digestion and metabolism each exhibit circadian patterns ${ }^{(16-18)}$. For example, in a British cohort, increasing energy intake from carbohydrates at the expense of a similar amount of energy from fat at breakfast and at mid-morning at the age of 43 years was associated with decreased prevalence of the metabolic syndrome 10 years later ${ }^{(19)}$. Another 6-year prospective cohort study in Italy has shown that a higher intake of energy at dinner was associated with higher incidence of obesity, the metabolic syndrome and non-alcoholic fatty liver disease ${ }^{(20)}$. Further, a traditional wheat-based breakfast identified by factor analysis was associated with a decreased risk of hyperglycaemia in a 6-year prospective cohort study in Chinese adults, whereas rice-based traditional lunch and dinner were associated with an increased risk $^{(21)}$. Additionally, a 3-year prospective cohort study showed that an even distribution of daily protein intake across meals was

Abbreviations: BDHQ, Brief Diet History Questionnaire; DHQ, Diet History Questionnaire; DR, dietary record; MDHQ, Meal-based Diet History Questionnaire.

* Corresponding author: Dr Kentaro Murakami, fax +8135841 7873, email kenmrkm@m.u-tokyo.ac.jp 
independently associated with greater muscle strength, but not with the mobility score, in older Canadian adults ${ }^{(22)}$.

Unfortunately, research on these topics is constrained by the fact that the primary method of dietary assessment currently employed in most cross-sectional and prospective cohort studies is FFQ, which precludes an informed evaluation of the timing of dietary intake and meal-specific dietary intake ${ }^{(23)}$. This kind of information can be derived from more detailed dietary assessment methods such as dietary record (DR) and 24-h dietary recall $^{(9)}$. However, when using these methods, collection of dietary data over multiple days is essential for the assessment of habitual intake at the individual level and is still not always feasible because of its expensive and burdensome nature ${ }^{(24)}$. Taken together, the development of dedicated fit-for-purpose methodology for collecting data on meal patterns and time of day of dietary intake which is also inexpensive to administer and has low participant burden is required to efficiently advance this new research field ${ }^{(9)}$.

In this study, we developed the Meal-based Diet History Questionnaire (MDHQ), a self-administered questionnaire designed for estimating food and nutrient intakes for each meal type separately. This was done based on actual food consumption data obtained from a Japanese population.

\section{Methods}

\section{General concept of the Meal-based Diet History} Questionnaire

Our main aim was to develop a self-administered diethistory type questionnaire for estimating food and nutrient intakes for each meal type separately (i.e. MDHQ). We also intended that the time taken to complete the MDHQ should be a compromise between that taken to complete the 288-item Diet History Questionnaire (DHQ; 30-45 min) ${ }^{(25-28)}$ and the seventy-three-item Brief Diet History Questionnaire (BDHQ; 10-15 min) ${ }^{(26-28)}$.

As shown in Fig. 1, the MDHQ consisted of the three different parts. Supplementary Fig. S1 shows the MDHQ translated into English. Part 1 of the MDHQ included quantitative questions on consumption frequency of generic food groups (herein referred to as Tier 1 food groups) for each meal type, with potential answers of $0-7 \mathrm{~d} /$ week. In this way, the MDHQ can collect dietary information needed for meal patterns and time of day of dietary intake, which cannot be derived from the DHQ or BDHQ. We decided a priori not to collect information on portion sizes (except for alcoholic beverages, for which the amount of each beverage consumed for a typical drinking occasion was asked in Part 2). This decision was mainly based on our previous observation that the BDHQ, which does not collect information on portion sizes and applies fixed portion sizes for dietary intake calculation, had similar efficacy in estimating food and nutrient intakes to the DHQ, where information on portion sizes is collected ${ }^{(26,27)}$. Limited usefulness of portion size information is also supported by several previous studies ${ }^{(29,30)}$.

Part 2 of the MDHQ included questions on relative consumption frequency of sub-food groups (herein referred to as Tier 2 food groups) within one of the generic food groups

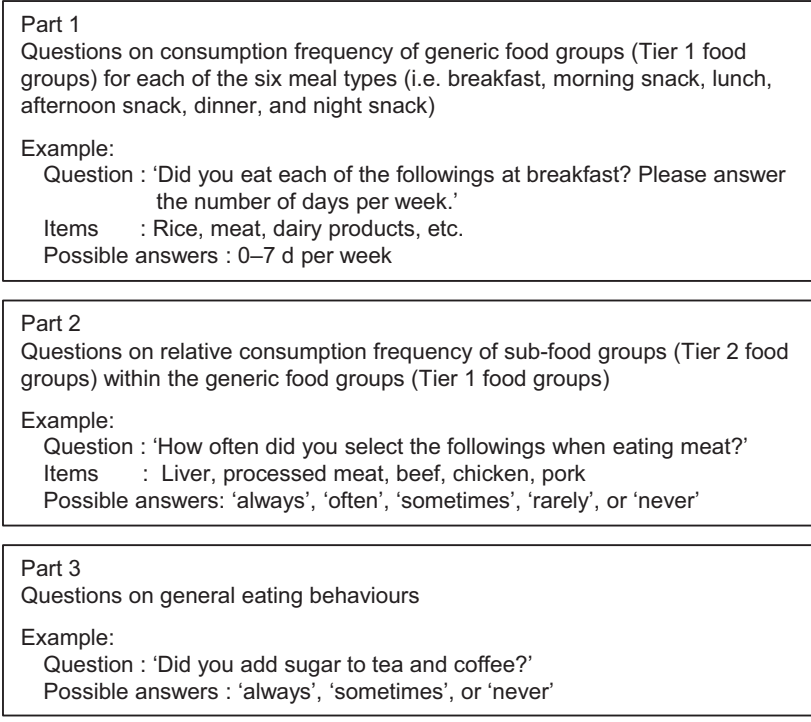

Fig. 1. A brief description on the structure of the Meal-based Diet History Questionnaire, with examples of questions.

(Tier 1 food groups), with possible answers of 'always', 'often', 'sometimes', 'rarely' and 'never'. By combining information derived from Parts 1 and 2, we are able to increase the number of foods we can estimate efficiently but within a limited number of questions.

Part 3 of the MDHQ asks about general eating behaviours, which are intended to use in a variety of ways during dietary intake calculation as described below. The reference time period was defined as the preceding month, to correspond with the time frame of both the DHQ and BDHQ.

\section{Data source}

The MDHQ, including its dietary intake calculation algorithm, was developed based on a 16-d DR obtained from a group of Japanese adults. The food consumption data were collected between November 2002 and September 2003 in four geographically diverse areas in Japan: Osaka (urban), Okinawa (urban island), Nagano (rural inland) and Tottori (rural coastal). Details of the survey have been described elsewhere ${ }^{(26-28,31,32)}$. In brief, the target population consisted of apparently healthy, community-dwelling women and their cohabitating spouses. Our recruitment strategy was such that each 10-year age category (30-39, 40-49, 50-59 and 60-69 years) included eight women for each area (without consideration of age of men), resulting in 256 invited participants. To minimise dropout rate, potential participants were restricted to individuals who gave us full understanding of the purpose, procedure and heavy burden of the survey and willingness to complete the entire survey. None of the sample was a dietitian, had experience with dietary counselling from a medical doctor or dietitian or had a history of hospitalisation for diabetes education.

Dietary data were collected by DR. The participants were requested to document and weigh all items eaten or drunk, both in and out of the home, over four non-consecutive days (three weekdays and one weekend day), once per season with 
an interval of about 3 months between surveys. At orientation, local dietitians explained to participants how to complete the DR using both written and verbal instructions, after which participants were provided with recording sheets and a digital scale. On occasions when weighing was problematic (e.g. eating out), participants were instructed to document as much information as possible, including the brand name of the food and the consumed portion size (based on typical household measures) as well as the details of leftovers. The recording sheets for each survey day were submitted directly to the local dietitian after the survey was completed, who then reviewed the forms and, whenever necessary, sought additional information or modification of the record via telephone or in person. All of the collected records were further reviewed by dietitians at the respective local centre and then again at the study centre. In accordance with standard procedures, portion sizes estimated using household measures were converted into weights and individual food items were coded based on the Standard Tables of Food Composition in Japan ${ }^{(33)}$. In total, 121 women aged 31-69 years and 121 men aged 31-81 years completed the study protocol; basic characteristics of the sample have been shown elsewhere ${ }^{(28,32)}$. Consequently, a total of 3872 DR data, including 206837 food item entries, comprised the basis for the MDHQ.

The food diary sheet used was based on a typical Japanese eating pattern, prescribed in the diary as breakfast, lunch, dinner and snacks. During the diet recording, participants were asked to record the clock time when consumption of a food or beverage started. We considered an eating occasion to be any named separate intake occasion with a discrete clock start time. Each eating occasion was then categorised into breakfast, lunch, dinner or snacks based on the section in the food diary in which it was recorded. Food intakes were calculated for each person for each day for each meal type.

The dietary study was conducted according to the guidelines laid down in the Declaration of Helsinki. The study purpose and protocol were explained before the study, and written informed consent was obtained from each participant. Use of data from the DR survey was approved by the University of Tokyo Faculty of Medicine Ethics Committee (project ID: 3421).

\section{Results}

In this section, we describe the development process of the MDHQ consisting of the following three parts, with a total of 196 items (Supplementary Fig. S1).

\section{Part 1 of the Meal-based Diet History Questionnaire:}

questions on Tier 1 food groups for each meal type

Determination of meal type. Part 1 of the MDHQ is shown on Pages 2-7 in Supplementary Fig. S1. Based on the DR data set, the mean clock start time at the individual level was 07.33 (sD 00.38) hours for breakfast, 12.25 (sD 00.28) hours for lunch and 19.17 (sD 00.57) hours for dinner, and mean daily snack frequency was 1.7 (SD 1.1). We thus included the following six meal types in Part 1 in the MDHQ: breakfast, morning snack, lunch, afternoon snack, dinner and night snack.
Selection of Tier 1 food groups. As shown previously ${ }^{(32)}$, each unique food item eaten by the participants in the DR data (approximately 1300 individual food item codes) was reclassified into 1 of 20 generic food groups (i.e. Tier 1 food groups): rice, bread, noodles, other grains, potatoes, pulses and nuts, vegetables, fruit, fish and shellfish, meat, eggs, dairy products, confectioneries, fruit and vegetable juice, alcoholic beverages, soft drinks, non-alcoholic and non-energetic beverages, sugars, fats and oils, and seasonings. Grouping of foods was done based on similarities in nutrient profile or culinary use of the foods, mainly in accordance with the Standard Tables of Food Composition in Japan ${ }^{(33)}$. After excluding three food groups usually consumed with other foods (sugars, fats and oils, and seasonings) as well as one food group (other grains), where intake at the population level was low ${ }^{(32)}$ and difficult to assess, there were sixteen Tier 1 food groups. Given their high intake in Japanese as well as their importance in food combinations ${ }^{(14,32)}$, non-alcoholic and non-energetic beverages were further divided into six food groups (i.e. green tea, barley tea, oolong tea, black tea, coffee and water), which were also classified into Tier 1 food groups for simplicity. Furthermore, we included miso soup and pickled vegetables as Tier 1 food groups because of their high intakes $^{(34)}$, although at the individual food item code level, the former was included in seasonings and the latter in vegetables. Finally, we included breakfast cereals as a Tier 1 food group (at the breakfast section only) because they could make a relatively large contribution to overall intake among habitual consumers, albeit that the number of appearances in the DR was quite small (i.e. nineteen appearances with a mean amount of $39 \mathrm{~g}$ ). We included these twenty-four Tier 1 food groups in Part 1 in the MDHQ, which are shown in the first column of Table 1.

To minimise the number of questions in the MDHQ, we developed a list of Tier 1 food groups for inclusion in each of the meal sections, based on the intake level of each Tier 1 food group at each meal ${ }^{(32)}$. These Tier 1 food groups predominantly consumed at every main meal but not as snacks (such as rice, vegetables and meat) were included in the breakfast, lunch and dinner sections, but not in the three snack sections. Conversely, we included confectioneries only in the sections on snacks because of their very low intake levels at main meals ${ }^{(32)}$. Since fruit, dairy products and beverages were commonly consumed at both main meals and snacks ${ }^{(32)}$, these were included in all eating occasion sections (except for the breakfast and morning snack sections for alcoholic beverages). The Tier 1 food groups for each meal type are summarised in the second to seventh columns of Table 1.

\section{Part 2 of the Meal-based Diet History Questionnaire: questions on Tier 2 food groups}

Part 2 of the MDHQ is shown on Pages 8-12 in Supplementary Fig. S1. After scrutinising the list of food item codes in the DR data set, we identified nine Tier 1 food groups within which there were food items that are distinctively different from each other in terms of either nutrient profile or culinary use. For each of these Tier 1 food groups, sub-food groups (i.e. Tier 2 food groups) were created based on food item codes, mainly in 
Table 1. Foods included in the Meal-based Diet History Questionnaire (MDHQ)*

\begin{tabular}{|c|c|c|c|c|c|c|c|}
\hline \multirow[b]{2}{*}{ Tier 1 food groups } & \multicolumn{6}{|c|}{ Meal type } & \multirow[b]{2}{*}{ Tier 2 food groups } \\
\hline & Breakfast & $\begin{array}{l}\text { Morning } \\
\text { snack }\end{array}$ & Lunch & $\begin{array}{l}\text { Afternoon } \\
\text { snack }\end{array}$ & Dinner & $\begin{array}{l}\text { Night } \\
\text { snack }\end{array}$ & \\
\hline Rice & $\mathrm{x}$ & & $\mathrm{x}$ & & $\mathrm{x}$ & & NA \\
\hline Bread & $\mathrm{x}$ & & $\mathrm{x}$ & & $\mathrm{x}$ & & NA \\
\hline Noodles & $\mathrm{x}$ & & $x$ & & $\mathrm{x}$ & & $\begin{array}{l}\text { Wheat noodles; Chinese noodles; instant noodles; spaghetti; } \\
\text { buckwheat noodles }\end{array}$ \\
\hline Miso soup & $\mathrm{X}$ & & $\mathrm{x}$ & & $\mathrm{x}$ & & NA \\
\hline Potatoes & $\mathrm{x}$ & & $\mathrm{x}$ & & $\mathrm{x}$ & & NA \\
\hline Pulses and nuts & $\mathrm{X}$ & & $\mathrm{X}$ & & $\mathrm{x}$ & & $\begin{array}{l}\text { Tofu (i.e. soyabean curd); natto (i.e. fermented soyabeans); } \\
\text { tofu products; soya milk; peanuts and nuts }\end{array}$ \\
\hline Vegetables & $\mathrm{X}$ & & $x$ & & $\mathrm{x}$ & & $\begin{array}{l}\text { Cabbage; cucumbers; lettuce; bitter melon; burdock; radishes; } \\
\text { onions; carrots; pumpkins; tomatoes; eggplants; green } \\
\text { peppers; broccoli; Chinese cabbage; green leafy vegetables; } \\
\text { bean sprouts; edamame (i.e. immature soyabeans) and } \\
\text { peas; mushrooms; seaweeds }\end{array}$ \\
\hline Pickled vegetables & $\mathrm{x}$ & & $\mathrm{x}$ & & $\mathrm{x}$ & & NA \\
\hline Fruit & $\mathrm{X}$ & $\mathrm{x}$ & $\mathrm{x}$ & $\mathrm{x}$ & $\mathrm{x}$ & $\mathrm{X}$ & $\begin{array}{l}\text { Strawberries; persimmons; citrus; kiwi fruit; water melons; } \\
\text { pears; bananas; grapes; melons; peaches; apples }\end{array}$ \\
\hline Fish and shellfish & $\mathrm{X}$ & & $\mathrm{x}$ & & $\mathrm{x}$ & & $\begin{array}{l}\text { Small fish with bones; dried fish; canned tuna; salmon; white meat } \\
\text { fish; oily fish; red meat fish; squid and octopus; eel; shrimp and } \\
\text { crab; shellfish; fish eggs; ground fish meat products }\end{array}$ \\
\hline Meat & $\mathrm{X}$ & & $\mathrm{x}$ & & $\mathrm{x}$ & & Liver; processed meat; beef; chicken; pork \\
\hline Eggs & $\mathrm{X}$ & & $\mathrm{x}$ & & $\mathrm{x}$ & & NA \\
\hline Dairy products & $\mathrm{X}$ & $\mathrm{x}$ & $\mathrm{x}$ & $\mathrm{X}$ & $\mathrm{x}$ & $\mathrm{x}$ & Low-fat milk; full-fat milk; yogurt; cheese; ice cream \\
\hline Confectioneries & & $\mathrm{x}$ & & $\mathrm{X}$ & & $\mathrm{X}$ & $\begin{array}{l}\text { Rice crackers; Japanese sweets; candies, caramels and } \\
\text { chewing gum; Japanese bread with a sweet filling; snacks } \\
\text { made from wheat flour; jellies; chocolates; biscuits and } \\
\text { cookies; cakes }\end{array}$ \\
\hline $\begin{array}{l}\text { Fruit and vegetable } \\
\text { juice }\end{array}$ & $\mathrm{X}$ & $\mathrm{x}$ & $\mathrm{x}$ & $\mathrm{x}$ & $\mathrm{x}$ & $\mathrm{x}$ & NA \\
\hline Alcoholic beverages & & & $\mathrm{x}$ & $\mathrm{x}$ & $\mathrm{x}$ & $\mathrm{X}$ & $\begin{array}{l}\text { Beer; sake; shochu (i.e. Japanese distilled beverages); } \\
\text { wine; whiskey and other spirits }\end{array}$ \\
\hline Soft drinks & $\mathrm{X}$ & $\mathrm{x}$ & $\mathrm{x}$ & $\mathrm{x}$ & $\mathrm{x}$ & $\mathrm{x}$ & NA \\
\hline Green tea & $\mathrm{x}$ & $\mathrm{x}$ & $\mathrm{x}$ & $\mathrm{x}$ & $\mathrm{x}$ & $\mathrm{x}$ & NA \\
\hline Barley tea & $\mathrm{X}$ & $\mathrm{x}$ & $\mathrm{x}$ & $\mathrm{x}$ & $\mathrm{x}$ & $\mathrm{x}$ & NA \\
\hline Oolong tea & $\mathrm{X}$ & $\mathrm{x}$ & $\mathrm{x}$ & $\mathrm{x}$ & $\mathrm{x}$ & $\mathrm{X}$ & NA \\
\hline Black tea & $\mathrm{x}$ & $\mathrm{x}$ & $\mathrm{x}$ & $\mathrm{x}$ & $\mathrm{x}$ & $\mathrm{x}$ & NA \\
\hline Coffee & $\mathrm{X}$ & $\mathrm{x}$ & $\mathrm{x}$ & $\mathrm{x}$ & $\mathrm{x}$ & $\mathrm{x}$ & NA \\
\hline Water & $\mathrm{X}$ & $\mathrm{X}$ & $\mathrm{X}$ & $\mathrm{x}$ & $\mathrm{x}$ & $\mathrm{x}$ & NA \\
\hline Breakfast cereals & $x$ & & & & & & NA \\
\hline
\end{tabular}

NA, not applicable.

* The MDHQ (Supplementary Fig. S1) consists of the following three parts. Part 1 includes questions on the consumption frequency as the number of d/week for each of the Tier 1 food groups for each of the meal types as shown above; questions on portion size are not included. In Part 2, for some of the Tier 1 food groups (i.e. noodles, pulses and nuts, vegetables, fruit, fish and shellfish, meat, dairy products and confectioneries), relative consumption frequency of sub-food groups (i.e. Tier 2 food groups) within the Tier 1 food group is asked, with possible answers of 'always', 'often', 'sometimes', 'rarely' and 'never'; for alcoholic beverages, the amount of each beverage consumed for a typical drinking occasion is answered by selecting one of seven possible answers. Part 3 asks about eating behaviours, as shown in Table 2.

accordance with individual food items used in the $\mathrm{DHQ}^{(25,26)}$.

For example, Tier 2 food groups for dairy products included low-fat milk, full-fat milk, yogurt, cheese and ice cream; Tier 2 food groups for other Tier 1 food groups are shown in the last column of Table 1 . A sum of these Tier 2 food groups accounted for $87-100 \%$ of total amount of the respective Tier 1 food group consumed in the DR data set. These Tier 2 food groups were included in Part 2 in the MDHQ.

\section{Part 3 of the Meal-based Diet History Questionnaire: questions on eating behaviours}

Part 3 of the MDHQ (Pages 13-14 in Supplementary Fig. S1) consisted of eighteen questions on eating behaviours in the $\mathrm{BDHQ}^{(26-28)}$, including the relative amounts of white rice and main and side dishes consumed. Information from Part 3 is applied during several calculations as described below; a summary is provided in Table 2 .

\section{Calculation algorithm in the Meal-based Diet History Questionnaire}

Tier 1 food groups. We developed an ad hoc computer algorithm for calculating food and nutrient intake based on the MDHQ. Detailed descriptions are provided in Table 3. Briefly, the intake of each of Tier 1 food groups at each of the meal types is calculated as the consumption frequency (from Part 1) multiplied by sex-specific and meal-type-specific portion size as well as by weighting factor(s) (e.g. a factor determined by age using the Estimated Energy Requirement $\left.{ }^{(35)}\right)$. For each of Tier 1 food groups, sex-specific and meal-type-specific portion size was defined as the mean of the intake value of the respective Tier 
Table 2. Eating behaviours asked in Part 3 in the Meal-based Diet History Questionnaire (MDHQ) ${ }^{*}$

\begin{tabular}{|c|c|}
\hline Eating behaviours & Possible answers \\
\hline Whether sugar is added to tea and coffee & Always, sometimes, never \\
\hline $\begin{array}{l}\text { Whether brown rice, germinated rice, wheat } \\
\text { or millet are mixed when white rice is } \\
\text { eaten }\end{array}$ & Always, sometimes, rarely, never \\
\hline $\begin{array}{l}\text { Consumption frequency of meat dishes } \\
\text { cooked using five different methods } \\
\text { (five separate questions) }\end{array}$ & $\begin{array}{l}\text { Twice per } d \text { or more, once per } d \text {, } \\
4-6 \text { times/week, } 2-3 \text { times/week, once } \\
\text { per week, less than once per week, } \\
\text { never }\end{array}$ \\
\hline $\begin{array}{l}\text { Consumption frequency of fish/shellfish } \\
\text { dishes cooked using four different } \\
\text { methods (four separate questions) }\end{array}$ & $\begin{array}{l}\text { Twice per } d \text { or more, once per } d \text {, } \\
4-6 \text { times/week, } 2-3 \text { times/week, once } \\
\text { per week, less than once per week, } \\
\text { never }\end{array}$ \\
\hline Preference for fatty meat & $\begin{array}{l}\text { Like very much, like a little, neither like nor } \\
\text { dislike, dislike a little, dislike very much }\end{array}$ \\
\hline Amount of noodle soup usually consumed & $\begin{array}{l}\text { Almost all, about } 80 \%, 40-60 \% \text { about } \\
20 \% \text {, almost nothing }\end{array}$ \\
\hline $\begin{array}{l}\text { Degree of taste strength compared } \\
\text { with eating out }\end{array}$ & $\begin{array}{l}\text { Weak, a little weak, same as eating out, } \\
\text { a little strong, strong }\end{array}$ \\
\hline
\end{tabular}
How to use

Frequency of soya sauce use

Always, often, sometimes, rarely, never

Very large, relatively large, typical, relatively small, very small

Amount of soya sauce usually used

Amount of main and side dishes usually consumed, in comparison with a typical amount in eating out

Amount of white rice usually consumed, in comparison with a typical amount in eating out

Very large at home, relatively large at home, same as eating out, relatively small at home, very small at home

Very large at home, relatively large at home, same as eating out, relatively small at home, very small at home
Sugar added to tea and coffee is estimated based on this question as well as intakes of coffee and black tea Based on this question, rice intake is divided into intakes of white rice and brown rice

Based on this question and intakes of meat and other foods usually accompanied in meat dishes (i.e. vegetables, eggs and potatoes), seasonings used during cooking (salt-taste seasonings, oils and sugars) are estimated

Based on this question and intakes of fish and shellfish as well as other foods usually accompanied in fish/shellfish dishes (i.e. vegetables, eggs, and potatoes), seasonings used during cooking (salt-taste seasonings, oils and sugars) are estimated

According to this question, different weighting factors are assigned to each food code categorised into beef, chicken and pork when estimating intakes of these foods.

Based on this question as well as intakes of wheat noodles, Chinese noodles, and buckwheat noodles, salt in noodle soup consumed is estimated

A weighting factor is created based on this question, which is used in a series of estimations, including seasonings used during cooking, salt in noodle soup, and soya sauce used at table. This question is also used to estimate jam and fat spread consumed with bread (with using information on bread intake) and dressing consumed with vegetables (with using information on vegetable intake)

Soya sauce used at table is estimated based on this question and the amount of soya sauce usually used

Soya sauce used at table is estimated based on this question and frequency of soya sauce use
A weighting factor is created based on this question, which is used when estimating intakes of all generic food groups (Tier 1 food groups) except for rice, bread, noodles, miso soup, breakfast cereals and beverages

A weighting factor is created based on this question, which is used when estimating intakes of staple foods (i.e. rice, bread, noodles and breakfast cereals) and miso soup

* The MDHQ (Supplementary Fig. S1) consists of the following three parts. Part 1 includes questions on the consumption frequency as the number of d/week for each of the Tier 1 food groups for each of the meal types (as shown in Table 1); questions on portion size are not included. In Part 2, for some of the Tier 1 food groups, relative consumption frequency of sub-food groups (i.e. Tier 2 food groups) within the Tier 1 food group is asked, with possible answers of 'always', 'often', 'sometimes', 'rarely' and 'never' (as shown in Table 1). Part 3 asks about eating behaviours, as shown above.

1 food group in the DR data. Fig. 2 shows an example of dietary intake calculation in the MDHQ. Here, the subject is a man aged 42 years, and the consumption frequency of noodles (a Tier 1 food group) at breakfast is $3 \mathrm{~d} /$ week. Thus, as shown in Fig. 1(a), noodles intake $(50 \cdot 7 \mathrm{~g} / \mathrm{d})$ is calculated as follows: (consumption frequency; $3 / 7$ here) $\times$ (sex-specific and mealtype-specific portion size in $g ; 129$ for men and breakfast) $x$ (weighting factor based on the information on relative amount of white rice from Part 3; e.g. 0.9 for 'relatively small at home') $\times$ (weighting factor based on age; e.g. 1.02 for men aged 42 years).

Tier 2 food groups. As shown in Table 3, the intake of each of Tier 2 food groups within the respective Tier 1 food group at each of the meal types is calculated on the basis of intake of the respective Tier 1 food group, meal-type-specific standard proportion of Tier 2 food groups and weighting factors created based on the information on relative consumption frequency (from Part 2). For each of the Tier 2 food groups, meal-type-specific standard proportion was defined as the amount of food consumed expressed as a percentage of all foods within the respective Tier 1 food group in the DR data. In the example shown in Fig. 2(b), it is assumed that the relative consumption frequency of Tier 2 food groups within noodles is as follows: 'rarely' (weighting factor 0.5) for wheat noodles, 'often' (weighting factor 3) for Chinese noodles, 'never' (weighting factor 0.0001) for instant noodles, 'always' (weighting factor 5) for spaghetti and 'sometimes' (weighting factor 1) for buckwheat noodles. Thus, intake of wheat noodles, a Tier 2 food group, $(11.7 \mathrm{~g} / \mathrm{d}$ ) is calculated as follows: (Tier 1 food intake in $\mathrm{g} / \mathrm{d}$; here, noodles: $50 \cdot 7) \times$ (meal-type-specific standard proportion of the Tier 2 food group in \%; 52.0 for wheat noodles at breakfast) $\times$ (weighting factor for the Tier 2 food group; 
Table 3. Calculation algorithm used in the Meal-based Diet History Questionnaire (MDHQ)*

\begin{tabular}{|c|c|c|}
\hline Dietary variables & Equation & Explanation \\
\hline Tier 1 food groups $†$ & $\begin{array}{l}\text { Intake }(\mathrm{g} / \mathrm{d})=(\text { consumption frequency as the number } \\
\text { of } \mathrm{d} / \text { week from Part } 1) / 7 \times(\text { sex-specific and } \\
\text { meal-type-specific portion size in } \mathrm{g}) \times \\
(\text { weighting factor(s) })\end{array}$ & $\begin{array}{l}\text { For each of Tier } 1 \text { food groups, sex-specific and meal-type- } \\
\text { specific portion size was defined as the mean of the intake value of } \\
\text { the respective Tier } 1 \text { food group in the DR data. A weighting factor } \\
\text { based on age was created as a ratio of the Estimated Energy } \\
\text { Requirement }{ }^{(35)} \text { for the participant's age to that for the mean age in } \\
\text { the DR data ( } 52 \text { years for men and } 50 \text { years for women). For staple } \\
\text { foods (i.e. rice, bread, noodles and breakfast cereals) as well as miso } \\
\text { soup, which is usually accompanied by rice, a weighting factor based } \\
\text { on the information on relative amount of white rice consumed (from } \\
\text { Part } 3 \text { ) is used. For other Tier } 1 \text { food groups, but except for all } \\
\text { beverages, a weighting factor based on the information on relative } \\
\text { amount of main and side dishes consumed (from Part } 3 \text { ) is used }\end{array}$ \\
\hline Tier 2 food groups $†$ & $\begin{array}{l}\text { Intake }(\mathrm{g} / \mathrm{d})=\text { (intake of the respective Tier } 1 \text { food } \\
\text { group in } \mathrm{g} / \mathrm{d}) \times(\text { meal-type-specific standard } \\
\text { proportion of the Tier } 2 \text { food group in } \%) \times \\
\text { (weighting factor for the Tier } 2 \text { food group)/ } \\
\Sigma((\text { meal-type-specific standard proportion of } \\
\text { each Tier } 2 \text { food group in } \%) \times \text { (weighting factor } \\
\text { for each Tier } 2 \text { food group) })\end{array}$ & $\begin{array}{l}\text { For each of the Tier } 2 \text { food groups, meal-type-specific standard } \\
\text { proportion was defined as the amount of food consumed expressed } \\
\text { as a percentage of all foods within the respective Tier } 1 \text { food group } \\
\text { in the DR data. A weighting factor was created based on the } \\
\text { information on relative consumption frequency from Part } 2 \text { (i.e. } 5 \text { for } \\
\text { 'always', } 3 \text { for 'often', } 1 \text { for 'sometimes', } 0.5 \text { for 'rarely' and } \\
0.0001 \text { for 'never') }\end{array}$ \\
\hline Other foods & - & $\begin{array}{l}\text { Intakes of a number of other foods are calculated based on information } \\
\text { on eating behaviours (from Part } 3 \text { ) as well as information on intakes of } \\
\text { Tier } 1 \text { and Tier } 2 \text { food groups (see Table } 2 \text { ) }\end{array}$ \\
\hline Energy and nutrients & $\begin{array}{l}\text { Intake (amount/d) }=\Sigma((\text { intake of food items in } \\
\text { Tier } 1 \text { or Tier } 2 \text { food groups and other foods } \\
\text { in } \mathrm{g} / \mathrm{d}) \times(\text { energy or nutrient content in } \\
\text { amount per } 100 \mathrm{~g} \text { of food }) / 100)\end{array}$ & $\begin{array}{l}\text { As both Tier } 1 \text { and Tier } 2 \text { food groups were determined based on the } \\
\text { dataset on actual food consumption (the DR data) consisting of indi- } \\
\text { vidual food item codes in the Standard Tables of Food Composition in } \\
\text { Japan }{ }^{(33)} \text {, each of the individual food item codes was given a value of } \\
\text { meal-type-specific standard proportion. Consequently, this compilation } \\
\text { (i.e. food item condes and meal-type-specific standard proportion val- } \\
\text { ues) is used for the calculation of energy and nutrient intakes. The } \\
\text { number of food codes included in this compilation is } 763 \text { for breakfast, } \\
909 \text { for lunch, } 965 \text { for dinner, } 695 \text { for morning snack and } 703 \text { for after- } \\
\text { noon and night snacks. The food composition databases used are the } \\
\text { Standard Tables of Food Composition in Japan }{ }^{(33)} \text {, the carbohydrate } \\
\text { section of the Standard Tables of Food Composition in Japan }{ }^{(36)} \text { and } \\
\text { the Japanese version }{ }^{(28,37)} \text { of the US Food Patterns Equivalents } \\
\text { Database }{ }^{(38)}\end{array}$ \\
\hline
\end{tabular}

DR, dietary record.

* The MDHQ (Supplementary Fig. S1) consists of the following three parts. Part 1 includes questions on the consumption frequency as the number of d/week for each of the Tier 1 food groups for each of the meal types (as shown in Table 1); questions on portion size are not included. In Part 2, for some of the Tier 1 food groups, relative consumption frequency of sub-food groups (i.e. Tier 2 food groups) within the Tier 1 food group is asked, with possible answers of 'always', 'often', 'sometimes', 'rarely' and 'never' (as shown in Table 1). Part 3 asks about eating behaviours (as shown in Table 2).

† For beer, sake, shochu (i.e. Japanese distilled beverages), wine, and whiskey and other spirits, intake at each meal type is calculated as daily consumption frequency of a Tier 1 food group alcoholic beverages (from Part 1) multiplied by the typical consumption amount of each beverage (from Part 2) and the weighting factor based on age. The sum of them constitutes the intake of a Tier 1 food group alcoholic beverages.

$0 \cdot 5$ here $) /(\Sigma(($ meal-type-specific standard proportion of each Tier 2 food group in \%) $\times$ (weighting factor for each Tier 2 food group)); here, $112 \cdot 8$, that is, $((52.0 \times 0.5$; for wheat noodles $)+(13.0 \times 3$; for Chinese noodles $)+(18.2 \times 0.0001$; for instant noodles $)+(7 \cdot 8 \times 5$; for spaghetti $)+(9 \cdot 0 \times 1$; for buckwheat noodles)).

For beer, sake, shochu (i.e. Japanese distilled beverages), wine, and whiskey and other spirits, intake at each meal type is calculated as daily consumption frequency of a Tier 1 food group alcoholic beverages (from Part 1) multiplied by the typical consumption amount of each beverage (from Part 2) and the weighting factor based on age. The sum of them constitutes the intake of a Tier 1 food group alcoholic beverages.

Other foods. Based on the information on eating behaviours (from Part 3) as well as information on intakes of Tier 1 and Tier 2 food groups, we developed calculation algorithms for intakes of a number of other foods, including sugar added to tea and coffee; seasonings (salt-taste seasonings, oils and sugars) used during cooking; salt in noodle soup; jam consumed with bread; fat spread consumed with bread; dressing consumed with vegetables; and soya sauce. These are summarised in Table 2 .

Energy and nutrients. Intakes of energy and nutrients are calculated as the intakes of Tier 1 or Tier 2 food groups multiplied by their nutrient compositions and then summing up these products (Table 3). In this calculation, relative amount of food items (food item codes) within the respective Tier 1 or Tier 2 food group in the DR data set is taken into account. The food composition tables used are the Standard Tables of Food Composition in Japan ${ }^{(33)}$, as well as the carbohydrate section of the Standard Tables of Food Composition in Japan ${ }^{(36)}$ and the Japanese version $^{(28,37)}$ of the US Food Patterns Equivalents Database ${ }^{(38)}$ (so that added sugars can be calculated). More specifically, 


\section{(a) Tier 1 food group \\ (b) Tier 2 food group \\ (c) Energy (an example)}

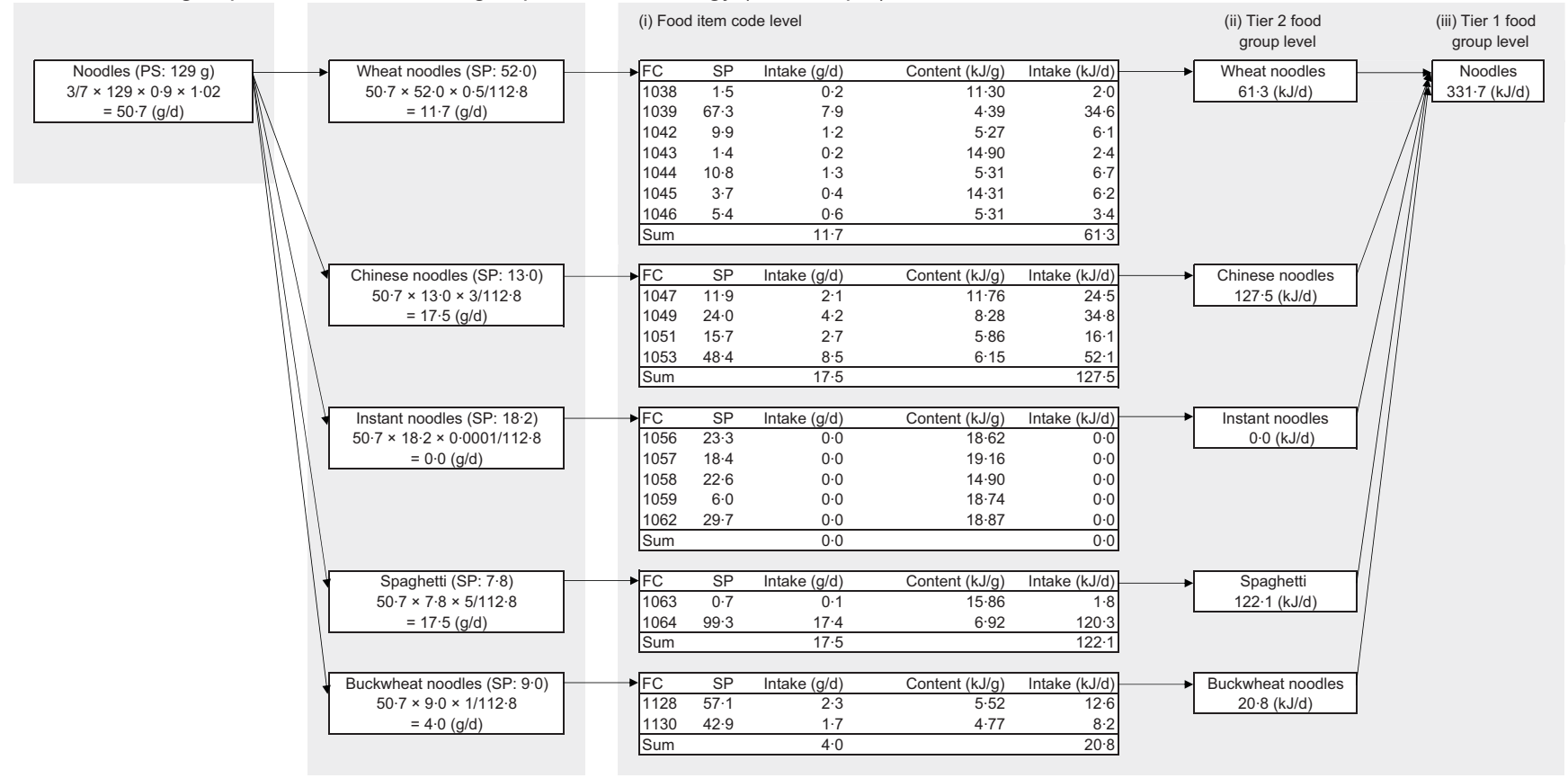

Fig. 2. An example of dietary intake calculation in the Meal-based Diet History Questionnaire. (a) Tier 1 food group. Here, the subject is a man aged 42 years, and the consumption frequency of noodles (a Tier 1 food group) at breakfast is $3 \mathrm{~d} /$ week. Then, noodles intake $(50.7 \mathrm{~g} / \mathrm{d}$ ) is calculated as follows: (consumption frequency; $3 / 7$ here) $\times$ (sex-specific and meal-type-specific portion size in g; 129 for men and breakfast) $\times$ (weighting factor based on the information on relative amount of white rice; e.g. 0.9 for 'relatively small at home') $\times$ (weighting factor based on age; e.g. 1.02 for men aged 42 years). (b) Tier 2 food group. Assume that the relative consumption frequency of Tier 2 food groups within noodles is as follows: 'rarely' (weighting factor 0.5) for wheat noodles, 'often' (weighting factor 3) for Chinese noodles, 'never' (weighting factor 0.0001) for instant noodles, 'always' (weighting factor 5) for spaghetti and 'sometimes' (weighting factor 1) for buckwheat noodles. Then, intake of wheat noodles, a Tier 2 food group, $(11.7 \mathrm{~g} / \mathrm{d}$ ) is calculated as follows: (Tier 1 food intake in $\mathrm{g} / \mathrm{d}$; here, noodles: 50.7$) \times($ meal-type-specific standard proportion of the Tier 2 food group in \%; 52.0 for wheat noodles at breakfast) $\times$ (weighting factor for the Tier 2 food group; 0.5 here)/( $\Sigma$ ((meal-type-specific standard proportion of each Tier 2 food group in \%) $\times$ (weighting factor for each Tier 2 food group)); here, 112.8 , that is, $(52.0 \times 0.5$; for wheat noodles $)+(13.0 \times 3$; for Chinese noodles $)+(18.2 \times 0.0001$; for instant noodles) $+(7.8 \times 5$; for spaghetti) $+(9.0 \times 1$; for buckwheat noodles)). (c) Energy (an example). The food composition database for each Tier 2 food group (and each Tier 1 food group without any Tier 2 food group) consists of individual food item codes, with values of meal-type-specific standard proportion. For example, a Tier 2 food group wheat noodles consists of seven individual food item codes. Thus, for energy intake calculation, wheat noodles intake is divided into these seven item codes, simply based on values of meal-type-specific standard proportion, and then intake for each item code is multiplied by its energy content; the sum of these products is energy intake from wheat noodles. In the same way, energy intake from a Tier 1 food group is calculated as the sum of energy intake from all Tier 2 food groups within the Tier 1 food group. PS, sex-specific and meal-type-specific portion size; SP, meal-type-specific standard proportion; FC, individual food item code.

the food composition database for each Tier 2 food group (and each Tier 1 food group without any Tier 2 food group) consists of individual food item codes, with values of meal-type-specific standard proportion. For example, as shown in Fig. 2(c), a Tier 2 food group wheat noodles consists of seven individual food item codes. Thus, for the calculation of energy intake (an example), wheat noodles intake $(11.7 \mathrm{~g} / \mathrm{d})$ is divided into these seven item codes, simply based on values of mealtype-specific standard proportion, and then intake for each item code is multiplied by its energy content; the sum of these products $(61.3 \mathrm{~kJ} / \mathrm{d})$ is energy intake from wheat noodles. In the same way, energy intake from a Tier 1 food group (noodles here; $331.7 \mathrm{~kJ} / \mathrm{d}$ ) is calculated as the sum of energy intake from all Tier 2 food groups $(61 \cdot 3,127 \cdot 5,0 \cdot 0,122 \cdot 1$ and $20 \cdot 8 \mathrm{~kJ} / \mathrm{d})$.

\section{Discussion}

Research on meal patterns and time of day of dietary intake has been hindered by the lack of fit-for-purpose dietary assessment questionnaires for estimating meal-specific dietary intakes.
Thus, we developed a self-administered, meal-based diet-history type questionnaire (i.e. MDHQ), on the basis of 3872 DR data in Japanese. To our knowledge, this is the first attempt at developing a self-administered dietary assessment questionnaire which can estimate intakes of foods and nutrients for each meal type separately, in addition to overall dietary intakes.

FFQ, including the DHQ and BDHQ, do not usually include the assessment of the timing of dietary intake and meal-specific dietary intake ${ }^{(9)}$. While detailed and thus burdensome methods such as DR and 24-h dietary recall are able to collect such information, multiple-day assessment is required for habitual intake, which is not always feasible in nutrition research despite the advancement of technology ${ }^{(39)}$. These led us to develop the MDHQ as a dedicated fit-for-purpose methodology for collecting data on meal patterns and time of day of dietary intake. While traditional FFQ including the DHQ and BDHQ ask about food intake on a daily basis (as a whole diet), the MDHQ is designed for collecting dietary information for each meal type separately. Given that the cognitive tasks required during dietary recall are complex, including understanding what information is being asked for, and searching for and evaluating the retrieved 
information before providing a response ${ }^{(40)}$, the MDHQ may be easier to answer, facilitating better estimation of food intake. This may be particularly relevant to Japanese because previous studies among Japanese adults have shown that the selection, amount and combination of foods consumed are markedly different between meal types ${ }^{(13-15,32)}$. An in-house pretest conducted with staff and students from the Department of Social and Preventive Epidemiology, University of Tokyo confirmed that the MDHQ took a median of 20 min to complete ( $n$ 16). This may suggest that the MDHQ is inexpensive to administer and has low participant burden, despite the fact that because of its complex structure and algorithms, dietary intake data for each meal type can be obtained. We believe that the MDHQ is a promising tool for advancing the new research area of meal patterns and time of day of dietary intake, or chrono-nutrition research. A validation study of this tool is warranted.

The strength of this study is the use of detailed information on actual food consumption, covering all seasons with a large number of records ( $n$ 3872), for the empirical development of the MDHQ and its calculation algorithm. However, there are also several limitations inherent in the dietary data used. First, all self-reported dietary assessment methods are subject to both random and systematic errors ${ }^{(41)}$, and the nature and extent of the measurement error of self-reported information on dietary intake from each meal type are largely unknown ${ }^{(42)}$. Our data-driven development of the MDHQ is not free from these problems. Second, although sampling for the dietary survey was conducted to consider regional differences in dietary habits, the population was not a nationally representative sample of the Japanese population. As volunteers, the participants may have been biased towards greater health consciousness. Further, as the participants (men and women) were from the same household, sex differences in dietary habits may have been under-represented. These factors might have affected the representation of some food items and portion sizes during the development of MDHQ. Theoretically speaking, with a more nationally representative dietary data, the MDHQ would have been more generalisable to Japanese. Nevertheless, we believe that the 3872 DR data used here are one of the most relevant one in Japan, mainly because the Japanese national dietary survey is based on a single-day DR at the household level, covering only 1 month of year ${ }^{(43)}$.

Although the MDHQ was developed for Japanese, the development was based on actual food consumption data and the process was highly standardised; thus, the same strategy could also be applied for other populations. This may be particularly promising in the context of international comparison of meal patterns and time of day of dietary intake or characterisation of Japanese diet, which is largely hindered by a lack of inexpensive dietary assessment tools for such purposes.

In conclusion, we described data-driven development of the MDHQ for Japanese adults. Given that the MDHQ was empirically developed based on comprehensive information on actual food consumption, this innovative tool may be useful as a dietary assessment tool for future epidemiological research on meal patterns and time of day of dietary intake, or chrononutrition research. Thus, a rigorous evaluation of validity of the MDHQ is warranted. We are now preparing for such a study to establish the integrity of both the paper-based and web-based versions of MDHQ for use in large-scale epidemiological studies.

\section{Acknowledgements}

The authors thank Naoko Hirota, Akiko Notsu, Ayako Miura, Hidemi Todoriki, Mitsuru Fukui and Chigusa Date for data collection in the dietary survey.

This study was funded by the H13 Health Sciences Research Grant (Kenkou-kagakusougoukenkyujigyou) from the Ministry of Health, Labour and Welfare, Japan. The Ministry of Health, Labour and Welfare had no role in the design, analysis or writing of this article.

K. M. conceptualised and developed the MDHQ, prepared the first draft of the manuscript and had primary responsibility for the final content; N. S. contributed to the conceptualisation and development of the MDHQ and assisted in the writing of the manuscript; T. A. M. and M. B. E. L. contributed to the conceptualisation of the MDHQ and provided critical input into the final draft of the manuscript and S. S. directed the dietary survey. All authors have read and agreed to the final version of the manuscript.

The authors declare that there are no conflicts of interest.

\section{Supplementary material}

For supplementary materials referred to in this article, please visit https://doi.org/10.1017/S0007114520004936

\section{References}

1. Hebert JR, Shivappa N, Wirth MD, et al. (2019) Perspective: the Dietary Inflammatory Index (DII)-lessons learned, improvements made, and future directions. Adv Nutr 10, 185-195.

2. Hu FB (2002) Dietary pattern analysis: a new direction in nutritional epidemiology. Curr Opin Lipidol 13, 3-9.

3. Newby PK \& Tucker KL (2004) Empirically derived eating patterns using factor or cluster analysis: a review. Nutr Rev 62, 177-203

4. Ax E, Warensjo Lemming E, Becker W, et al. (2016) Dietary patterns in Swedish adults; results from a national dietary survey. Br J Nutr 115, 95-104.

5. Gazan R, Bechaux C, Crepet A, et al. (2016) Dietary patterns in the French adult population: a study from the second French National Cross-sectional Dietary Survey (INCA2) (20062007). Br J Nutr 116, 300-315.

6. Hearty AP \& Gibney MJ (2009) Comparison of cluster and principal component analysis techniques to derive dietary patterns in Irish adults. BrJ Nutr 101, 598-608.

7. Kerver JM, Yang EJ, Obayashi S, et al. (2006) Meal and snack patterns are associated with dietary intake of energy and nutrients in US adults. I Am Diet Assoc 106, 46-53.

8. Myhre JB, Loken EB, Wandel M, et al. (2015) Meal types as sources for intakes of fruits, vegetables, fish and whole grains among Norwegian adults. Public Health Nutr 18, 2011-2021.

9. Leech RM, Worsley A, Timperio A, et al. (2015) Understanding meal patterns: definitions, methodology and impact on nutrient intake and diet quality. Nutr Res Rev 28, 1-21.

10. Jacobs DR Jr \& Steffen LM (2003) Nutrients, foods, and dietary patterns as exposures in research: a framework for food synergy. Am J Clin Nutr 78, 508S-513S. 
11. Andersson J, Nydahl M, Gustafsson K, et al. (2003) Meals and snacks among elderly self-managing and disabled women. Appetite 41, 149-160.

12. de Oliveira Santos R, Fisberg RM, Lobo Marchioni DM, et al. (2015) Dietary patterns for meals of Brazilian adults. $\mathrm{Br} J$ Nutr 114, 822-828.

13. Murakami K, Livingstone MBE, Shinozaki N, et al. (2020) Food combinations in relation to the quality of overall diet and individual meals in Japanese adults: a nationwide study. Nutrients $\mathbf{1 2}, 327$

14. Murakami K, Livingstone MBE \& Sasaki S (2017) Establishment of a meal coding system for the characterization of meal-based dietary patterns in Japan. J Nutr 147, 2093-2101.

15. Murakami K, Livingstone MBE \& Sasaki S (2019) Meal-specific dietary patterns and their contribution to overall dietary patterns in the Japanese context: findings from the 2012 National Health and Nutrition Survey, Japan. Nutrition 59, 108-115.

16. Arble DM, Bass J, Laposky AD, et al. (2009) Circadian timing of food intake contributes to weight gain. Obesity 17, 2100-2102.

17. Garaulet M \& Gomez-Abellan P (2014) Timing of food intake and obesity: a novel association. Physiol Behav 134, $44-50$.

18. Almoosawi S, Vingeliene S, Karagounis LG, et al. (2016) Chrono-nutrition: a review of current evidence from observational studies on global trends in time-of-day of energy intake and its association with obesity. Proc Nutr Soc 75, 487-500.

19. Almoosawi S, Prynne CJ, Hardy R, et al. (2013) Time-of-day and nutrient composition of eating occasions: prospective association with the metabolic syndrome in the 1946 British birth cohort. Int J Obes 37, 725-731.

20. Bo S, Musso G, Beccuti G, et al. (2014) Consuming more of daily caloric intake at dinner predisposes to obesity. A 6-year population-based prospective cohort study. PLOS ONE 9, e108467.

21. Shi Z, Riley M, Taylor A, et al. (2017) Meal-specific food patterns and the incidence of hyperglycemia in a Chinese adult population. Br J Nutr 118, 53-59.

22. Farsijani S, Payette H, Morais JA, et al. (2017) Even mealtime distribution of protein intake is associated with greater muscle strength, but not with 3-y physical function decline, in freeliving older adults: the Quebec longitudinal study on Nutrition as a Determinant of Successful Aging (NuAge study). Am J Clin Nutr 106, 113-124

23. Almoosawi S, Vingeliene S, Gachon F, et al. (2019) Chronotype: implications for epidemiologic studies on chrono-nutrition and cardiometabolic health. Adv Nutr 10,30-42.

24. Willett WC, ed. (2012) Nutritional Epidemiology, 3rd ed. New York: Oxford University Press.

25. Sasaki S, Yanagibori R, Amano K (1998) Self-administered diet history questionnaire developed for health education: a relative validation of the test-version by comparison with 3-day diet record in women. J Epidemiol 8, 203-215.

26. Kobayashi S, Murakami K, Sasaki S, et al. (2011) Comparison of relative validity for food group intake estimated by comprehensive and brief-type self-administered diet history questionnaires against $16 \mathrm{~d}$ dietary records in Japanese adults. Public Health Nutr 14, 1200-1211.

27. Kobayashi S, Honda S, Murakami K, et al. (2012) Both comprehensive and brief self-administered diet history questionnaires satisfactorily rank nutrient intakes in Japanese adults. J Epidemiol 22, 151-159.
28. Murakami K, Livingstone MBE, Fujiwara A, et al. (2019) Reproducibility and relative validity of the Healthy Eating Index-2015 and Nutrient-Rich Food Index 9.3 estimated by comprehensive and brief diet history questionnaires in Japanese adults. Nutrients 11, 2540.

29. Noethlings U, Hoffmann K, Bergmann MM, et al. (2003) Portion size adds limited information on variance in food intake of participants in the EPIC-Potsdam study. J Nutr 133, 510-515.

30. Schlundt DG, Buchowski MS, Hargreaves MK, et al. (2007) Separate estimates of portion size were not essential for energy and nutrient estimation: results from the Southern Community Cohort food-frequency questionnaire pilot study. Public Health Nutr 10, 245-251.

31. Murakami K, Sasaki S, Takahashi Y, et al. (2008) Reproducibility and relative validity of dietary glycaemic index and load assessed with a self-administered diet-history questionnaire in Japanese adults. Br J Nutr 99, 639-648.

32. Murakami K, Livingstone MBE, Sasaki S, et al. (2018) Applying a meal coding system to 16 -d weighed dietary record data in the Japanese context: toward the development of simple mealbased dietary assessment tools. J Nutr Sci 7, e29.

33. Council for Science and Technology; Ministry of Education, Culture, Sports, Science and Technology, Japan (2015) Standard Tables of Food Composition in Japan 2015, 7th rev. ed. Tokyo, Japan: Official Gazette Co-Operation of Japan (in Japanese).

34. Okubo H, Murakami K, Sasaki S, et al. (2010) Relative validity of dietary patterns derived from a self-administered diet history questionnaire using factor analysis among Japanese adults. Public Health Nutr 13, 1080-1089.

35. Ministry of Health, Labour and Welfare, Japan (2020) Dietary Reference Intakes for Japanese, 2020. https://www.mhlw.go. $\mathrm{jp} / \mathrm{content} / 10904750 / 000586553 . p d f$ (in Japanese; accessed May 2020).

36. Council for Science and Technology; Ministry of Education, Culture, Sports, Science and Technology, Japan (2015) Standard Tables of Food Composition in Japan 2015, Carbohydrate Section (7th revised edition). https://www.mext.go.jp/a_menu/ syokuhinseibun/1365452.htm (in Japanese; accessed May 2020).

37. Murakami K, Livingstone MBE, Fujiwara A, et al. (2020) Application of the Healthy Eating Index-2015 and the Nutrient-Rich Food Index 9.3 for assessing overall diet quality in the Japanese context: different nutritional concerns from the US. PLOS ONE 15, e0228318.

38. Bowman SA, Clemens JC, Friday JE, et al. (2014) Food Patterns Equivalents Database 2011-12: methodology and user guide. Food Surveys Research Group. Beltsville Human Nutrition Research Center, Agricultural Research Service, U.S. Department of Agriculture, Beltsville, MD. http://www.ars.usda.gov/nea/ bhnrc/fsrg (accessed May 2020).

39. Cade JE (2017) Measuring diet in the 21st century: use of new technologies. Proc Nutr Soc 76, 276-282.

40. Livingstone MB, Robson PJ, Wallace JM (2004) Issues in dietary intake assessment of children and adolescents. Br J Nutr $\mathbf{9 2}$, S213-S222.

41. Livingstone $\mathrm{MB}$ \& Black AE (2003) Markers of the validity of reported energy intake. J Nutr 133, 895S-920S.

42. Kant AK (2018) Eating patterns of US adults: meals, snacks, and time of eating. Physiol Behav 193, 270-278.

43. Ikeda N, Takimoto H, Imai S, et al. (2015) Data resource profile: the Japan National Health and Nutrition Survey (NHNS). Int J Epidemiol 44, 1842-1849. 